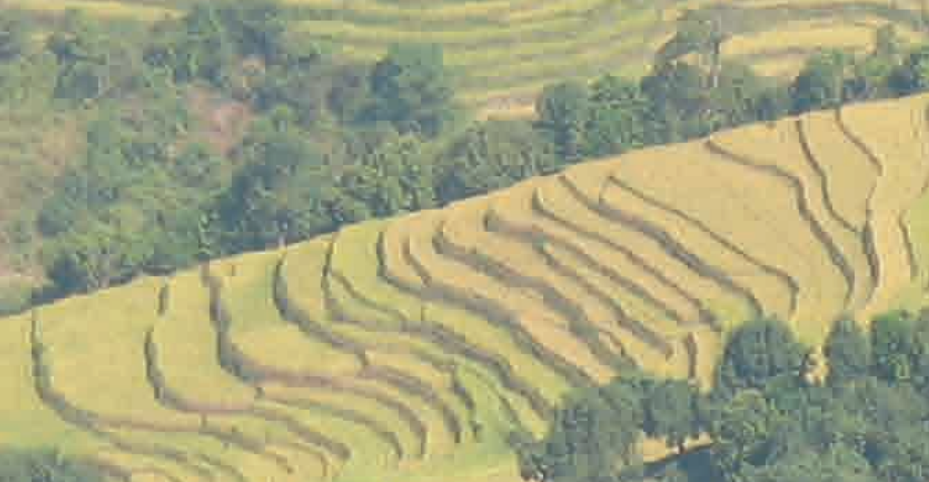

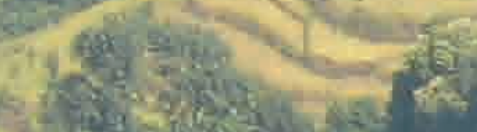
(3)

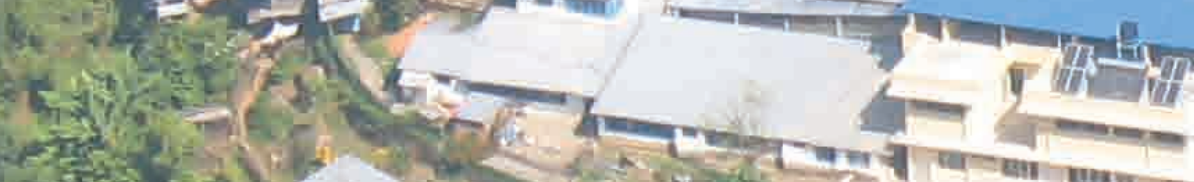

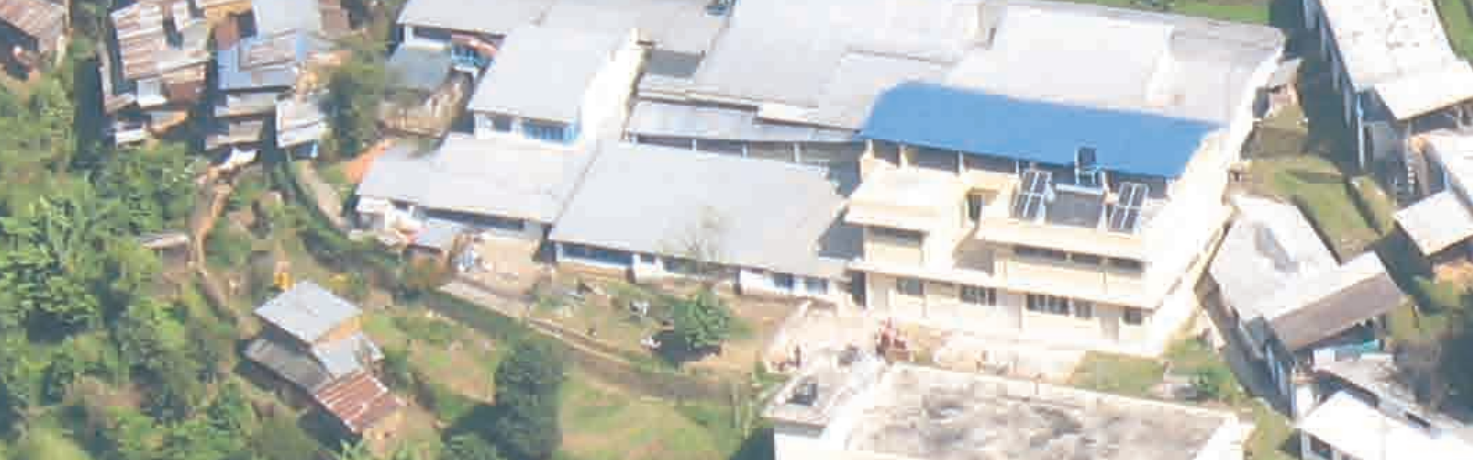

$$
\begin{aligned}
& \text { (1) } \\
& y, y=1-7
\end{aligned}
$$

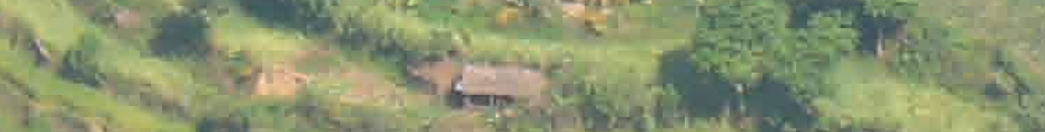

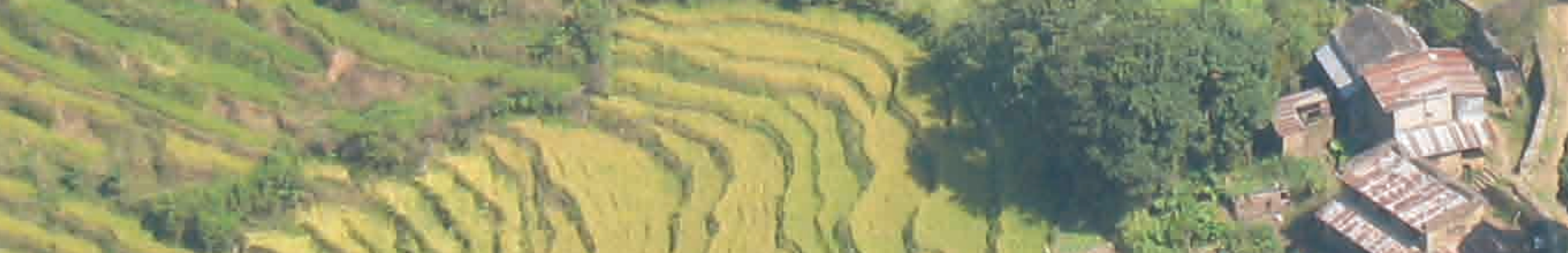

$$
\begin{aligned}
& \text { (5) }
\end{aligned}
$$




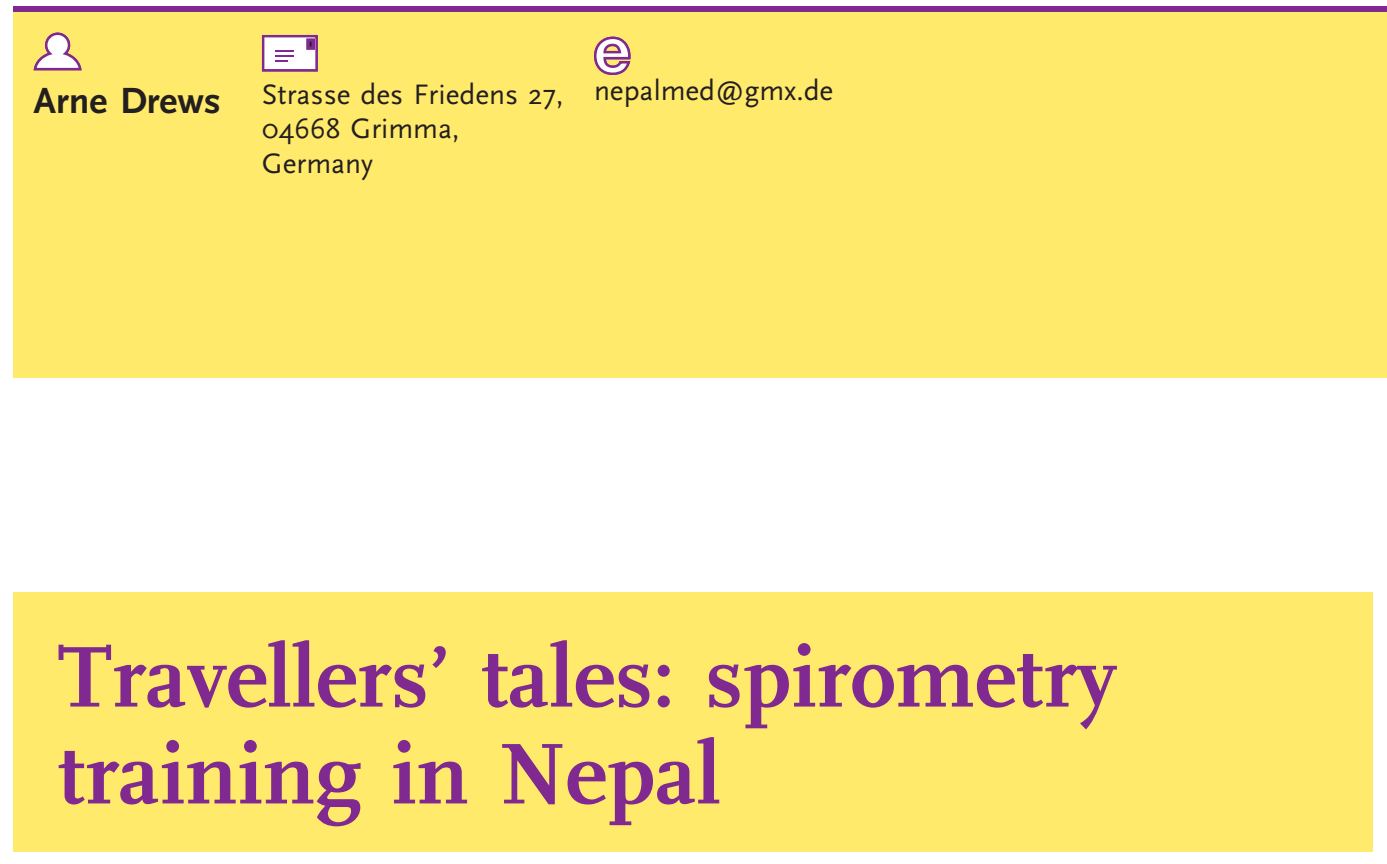

In Nepal there is very little functioning governmental healthcare at the hospital level for a population of around 29 million people. Most hospitals are private initiatives and patients have to pay cash for their treatment. The remote Amppipal Hospital in Gorkha district (fig. 1) is run by a local committee of villagers with the support of non-governmental organisations, like Nepalmed Germany. Nepalmed is a Germany-based group of volunteers from all over the world supporting Nepalese activities in the field of healthcare. The report on the World Spirometry Day 2012 event in the Nepalese capital Kathmandu in the September issue of Breathe [1] inspired me to write about my training sessions in Nepal. In Germany, I worked as a respiratory physician in private practice for 5 years, after a 10-year period spent working in teaching hospitals. In my spare time, I am chairman of Nepalmed and for 4 years have organised medical surveys in Amppipal, Nepal to learn more about the medical needs of the local population. This helps with planning of medication and equipment supplies. It also helps provide specialised physicians to teach the hospital personnel efficient diagnostic and therapeutic procedures.

\section{Spirometry training in Germany}

There has been no dedicated spirometry curriculum in Germany for doctors or nurses. A small group of German respiratory physicians, called The Doctor's Group for Diagnostic Lung Function, has promoted a standardised approach to teaching. This comprised a half-day session in two parts: a lecture on basic principles, followed by practical training using spirometers provided by the respiratory physician as well as the general practitioner's own spirometers. The event ended with case discussions and a written test, which is discussed after completion with all participants. After 12 years, an advanced course or a refresher course can be taken.

I perform between four and five spirometry training sessions per year for general practitioners and nurses, following the German group programme. Therefore, I was excited to read about the proposed ERS Spirometry Driving Licence programme and to attend the first train-the-trainer course at the Vienna congress in September, 2012. This course programme combined a standardised approach to teaching lung function across Europe with high-quality knowledge. It also builds a European spirit amongst respiratory physicians and nurses. For decades in Germany, in contrast to many other countries in Europe and across the Atlantic, body plethysmography has been established as a common diagnostic method among respiratory physicians, in hospitals as well as in general practice. However, many small hospitals and general practitioners opt for spirometry, which is easier and cheaper. For the future, there is a great need for better quality training. I took part in the ERS course to improve my teaching skills and learned a lot about teaching, especially about the importance of reviewing and reinforcing knowledge.
Statement of Interest None declared.
(C) 9 ERS 2013

HERMES syllabus link: module D.1.1, D.1.7

www.nepalmed.de 


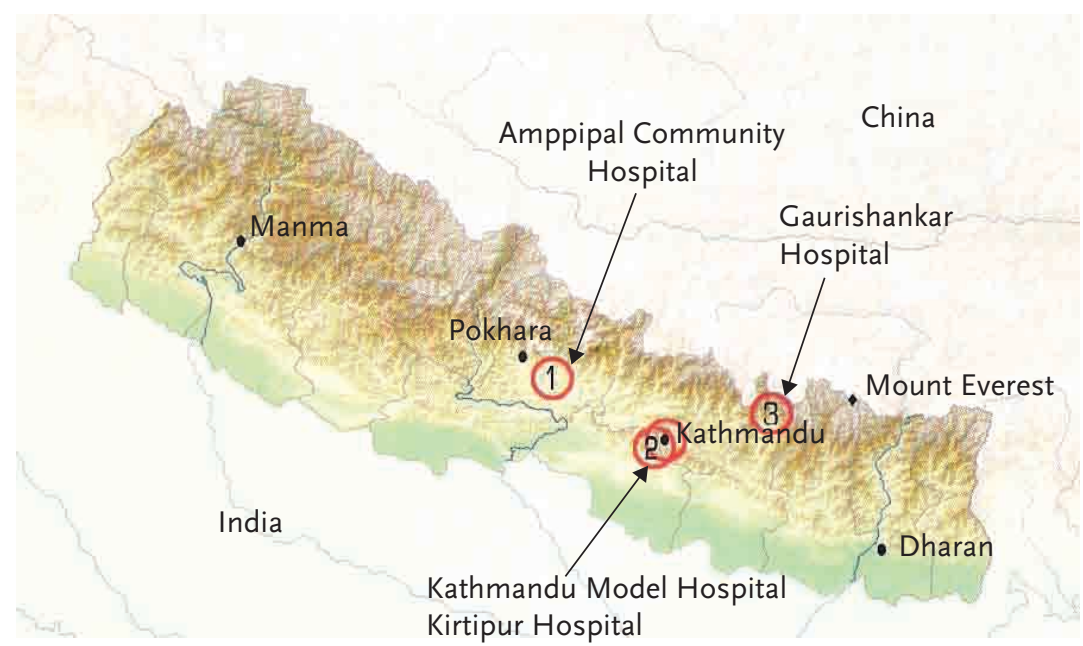

Figure 1

Map of Nepal showing the locations of the hospitals.

\section{Spirometry training in Nepal}

My last journey to Nepal was scheduled for October, 2012 when the ERS Spirometry Driving Licence materials were not yet available. I organise these trips for members and friends of Nepalmed who would like to travel with the support of someone experienced in this area. Our supporters can see the projects themselves and meet the partners, seeing for themselves where their donations go. Often new concepts and objects of support emerge during the tour and the participants develop a strong bond towards voluntary charity work.

During past surveys in Nepal we also included spirometry, because there are a great number of people with shortness of breath and coughing, due to infections and the smoke of

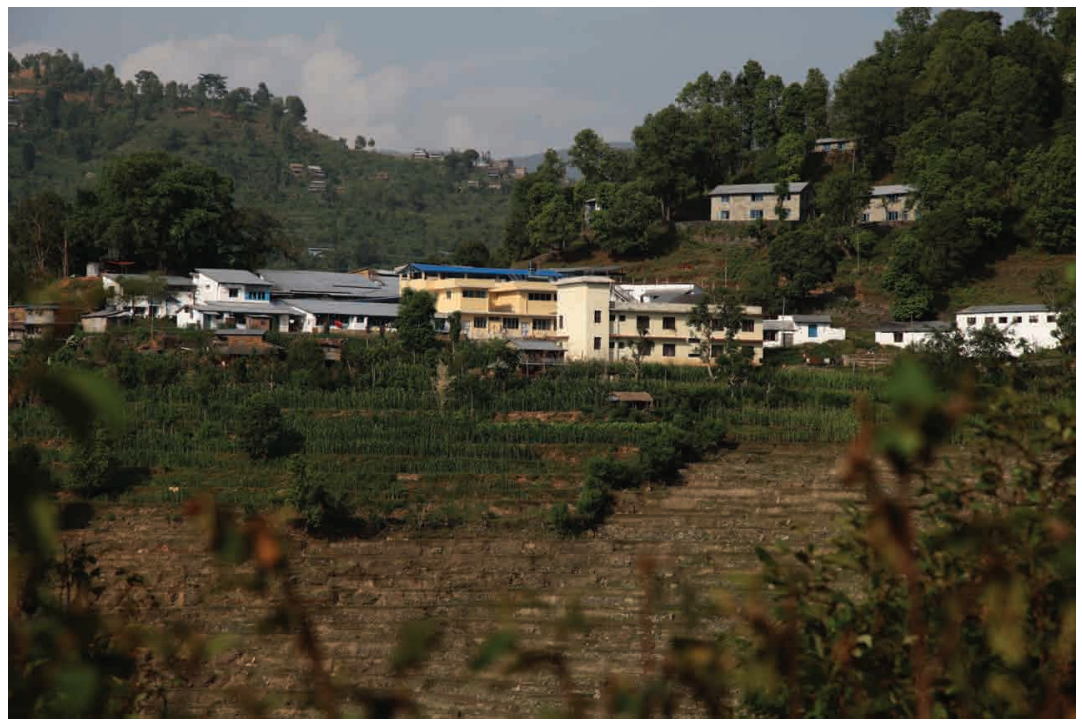

open fireplaces in the small cottages. Not very surprisingly, we found a high prevalence of chronic bronchitis and obstructive ventilatory disorders, averaging $22 \%$ in males and $14 \%$ in females presenting to the hospital during autumn and winter months. The results were presented at the ERS congresses in Vienna 2009 [2] and Barcelona 2010 [3].

For my visit in October 2012, I ordered a number of lung function textbooks for our Nepalese partner hospitals from the British Association for Respiratory Technology and Physiology (ARTP) because the proposed course system for the ERS Spirometry Driving Licence resembles their programme. In the week before Christmas 2012, I received information from the ERS course co-ordinators about the curriculum, the application procedures and papers that should be used in teaching Spirometry under this approach.

\section{Spirometry in Nepal}

In Nepal, there are very few spirometers available or in use. At the Tribhuvan University Teaching Hospital, Maharajgunj, Kathmandu, there is one spirometer. The doctors have used this to conduct small respiratory surveys. Hardly any other hospitals perform lung function diagnosis. Raising awareness of respiratory medicine among professionals is badly needed, as is equipment.

For our first survey in Amppipal Hospital in 2008, I taught a German student in my own practice spirometry for 1 week during normal working hours. We sent him to Nepal with the EasyOne device (NDD Medical Technologies, Inc., Andover, MA, USA). This is a robust system and gives the opportunity to collect and process data on a notebook computer. We also provided many spare mouthpieces, disinfection solution and laminated instruction sheets, in English, about the procedures and basic interpretation of results. The student performed well and instructed the local nurses. He measured nearly 600 patients identifying a high number of patients with airway obstruction. In $14 \%$ of all spirometries we found an obstruction; in $12 \%$ of females ( 42 out of 337 ) and $22 \%$ of males (41 out of 190). One immediate result of the finding of high number of subjects with airway obstructions was to send a young man from the village to learn how to construct smoke-free ovens, from locally available materials at an affordable 
price. Since then, he has built more than 400 ovens in the area. Instructional videos about smoking cessation have also been shown on a television set in the waiting area of the outpatient department.

In preparation for the journey in October, we enquired into the need for further spirometry training amongst the partner hospitals in Amppipal, Kirtipur and the Model Hospital Kathmandu and they were all interested. Nepalmed bought three identical spirometers from Microlab (CareFusion Health, Hoechberg, Germany) and I planned the teaching sessions. My practice nurses accompanied me and assisted with teaching lung function, as well as taking the opportunity to visit Nepal and its World Heritage sites. They were overwhelmed by the colourful culture with its multitude of temples and shrines, in sharp contrast to the overpopulation, noise and pollution in the Kathmandu metropolitan area. After 2 days, we left for the remote village Amppipal in the mid-western hill region. It is a full day's journey along deep gorges with wild rivers and lush green forests. Amppipal Hospital is situated on the western slope of Mount Liglig at an altitude of $1020 \mathrm{~m}$, amidst green terraced fields of rice, mustard and millet. Since the monsoon season was already over we had wonderful dry, warm and sunny weather with spectacular views of the snowcapped peaks of the Himalayas.

We knew that there is only one young Nepalese doctor in Amppipal. He and the six nurses were eager to learn about lung function testing. Some of the nurses had already received training in spirometry from our German student during the airway survey. Now we had to introduce them to the newly donated spirometer, which remains in Amppipal. I started teaching with lectures on anatomy and pathophysiology, indications, definition of spirometric values, equipment, technique and interpretation. Afterwards my nurses practiced with each of the Nepalese nurses using the device. By the end, all of the participants felt confident to perform spirometry independently in the future. We provided them with the ARTP Spirometry textbook, a short concise booklet about spirometry with case discussions and fact sheets for patients.

In Kathmandu, we organised a bigger group of participants due to our very full schedule. We had a lot of appointments with the embassy, medical suppliers, supporters and friends. Six doctors and eight nurses

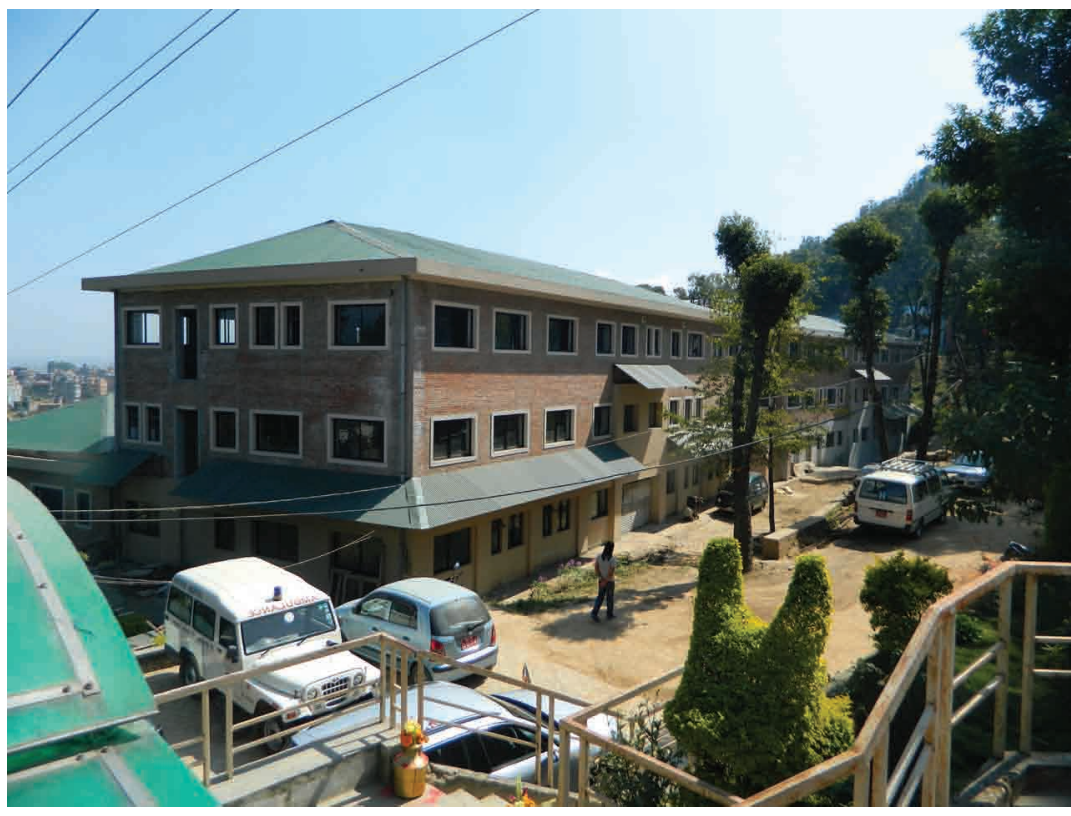

from both Model Hospital Kathmandu and Kirtipur hospital attended the meeting. I started again with the lectures for the entire group. In the second part, the nurses trained on the spirometer with the three nurses from my practice. Meanwhile, the doctors discussed curve interpretation and problem cases. For some of the nurses from the Model Hospital it was a refresher course, because a year ago Nepalmed introduced spirometry in order to conduct a survey of allergic respiratory diseases. The data collection finished in December 2012, after inclusion of more than 200 patients.

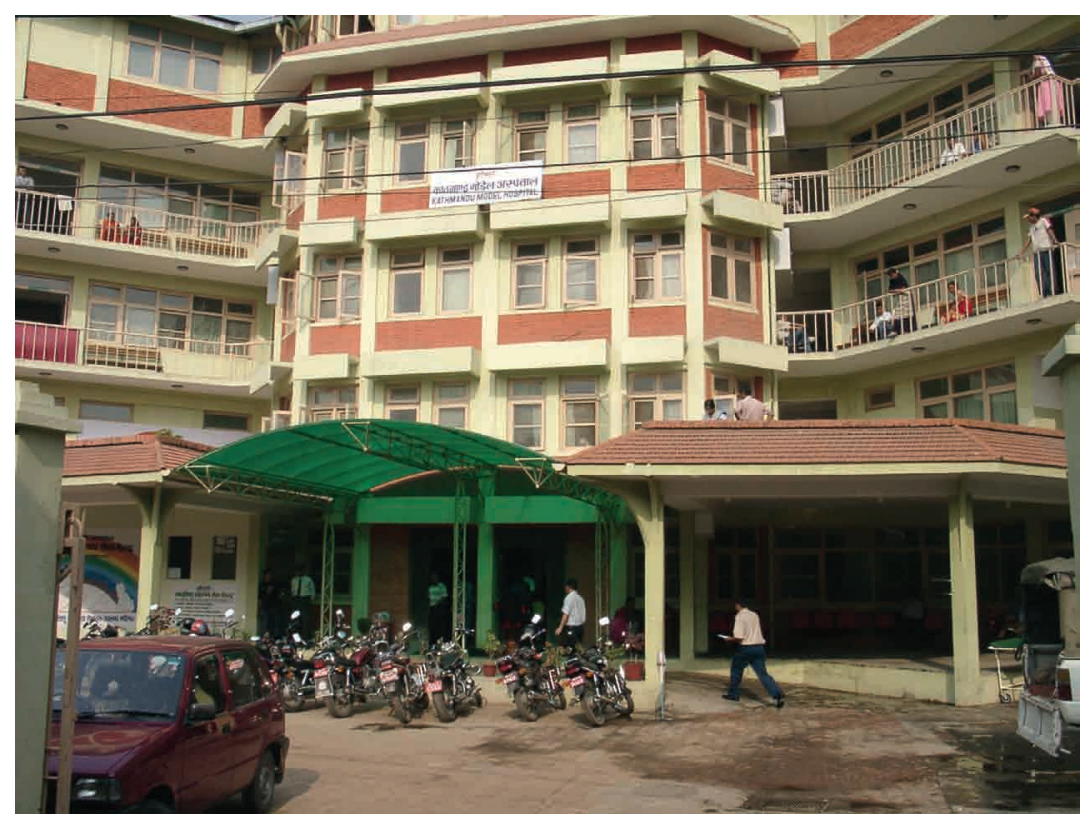


This gave them plenty of time to practice. Now it comes to the point of translating the training into practical use on the ward and in outpatient departments. In March 2013, a German medical student, who trained in my practice, will go to Amppipal and the Model Hospital to check the correct usage of the device, as well as to discuss hygiene and answer questions.

\section{Training in the future}

With the new ERS Spirometry Driving Licence training manual now at hand, we are planning a session in Kathmandu for refreshing training, as well as a complete, but probably abbreviated new course. The core modules, including the practical training, have to be shortened to fit into a one day event. This is necessary because the Nepalese working week permits only one day off, on Saturday. Sunday is the start of the week. The most challenging points will be the implementation of the intercontinental filling-in and submission of the Spirometry Workbook from participants in Nepal to Germany. Another near-impossible task is the online completion of module 1 (anatomy) due to very slow internet connections and very frequent power cuts.

Respiratory medicine in Nepal has not reached the importance it should have, either in the educational curricula or in every day clinical practice, considering the high prevalence of airway disorders. From our experience with the events in Nepal and the feedback from the participants we know that there is considerable interest and need for further training opportunities in lung function for the doctors and nurses in this country. It has to be discussed whether it would be suitable to sail under the ERS Spirometry Driving License flag or establish something similarly meaningful for Nepal.

\section{References}

1. Fletcher M, Rabe K. World spirometry day 2012: the highlights so far. Breathe 2012; 9: 5-8.

2. Drews A, Bergmann T, Scheuch K, et al. Adults in rural Nepal: are respiratory diseases frequent? Eur Respir J 2009; 34: Suppl. 53, 626s.

3. Drews A, John G, Bergmann T, et al. Adults in rural Nepal: are obstructive ventilatory disorders frequent? Eur Respir J 2010; 36: Suppl. 54, 767s.

From the ERS Education Department:

We were interested to read the inspiring article by Dr Drews, and congratulate him on his work in Nepal, bringing spirometry training to the country. Dr. Drews illustrates the challenges in delivering spirometry training at a local level.

As the ERS European Spirometry Driving Licence is coming to fruition, we have had proposals to disseminate the ERS Spirometry training programme to many countries, including Denmark, Italy, Georgia, New Zealand and Australia, each with their own set of unique difficulties to address.

Dr. Drews correctly highlights the efforts that would be required to overcome challenges such as differences in cultural working practices, intermittent electricity and internet, and a lack of experienced spirometry trainers to disseminate the programme. From applications received, other issues have been brought to our attention including the prescribed mandatory requirement within the programme structure that all course directors must attend the European based spirometry train-the-trainer programme and the issue of how we can maintain the quality of ERS spirometry training programmes delivered in the other side of the world.

The ERS spirometry task force and working group led by Brendan Cooper (UK), and Irene Steenbruggen (The Netherlands) are keen to assist local trainers to deliver the prescribed programme, and are confident that with the simple educational structure and flexible model designed by this task force, their aim to standardise training and certification in spirometry will be accomplished.

We look forward to working with Dr Drews and other trainers in addressing these issues and meeting the challenges in bringing standardised spirometry training, through the European Spirometry Driving License, to many countries. 